\title{
Potencial antiviral da quercetina sobre o parvovírus canino
}

\author{
[Antiviral potencial of quercetin in canine parvovirus] \\ O.V. Carvalho ${ }^{1,2}$, F.S. Oliveira ${ }^{3}$, G.L. Saraiva ${ }^{1}$, C.V. Botelho ${ }^{1}$, H.C.C. Ferreira ${ }^{1}$, \\ M.R. Santos ${ }^{1}$, A. Silva Júnior ${ }^{1,3}$, M.R. Almeida ${ }^{3 *}$ \\ ${ }^{1}$ Universidade Federal de Viçosa - Viçosa, MG \\ ${ }^{2}$ Instituto de Veterinária - Universidade Federal Rural do Rio Janeiro - Seropédica, RJ \\ ${ }^{3}$ Bioagro - Universidade Federal de Viçosa - Viçosa, MG
}

\begin{abstract}
RESUMO
Avaliou-se o efeito do flavonoide quercetina na replicação do parvovírus canino in vitro por meio do ensaio de determinação da atividade virucida (ensaio 1), ensaio de determinação da atividade sobre a célula (ensaio 2) e ensaio de tempo de adição das drogas em diferentes etapas do ciclo replicativo viral (ensaio 3). A quercetina apresentou significante atividade antiviral, com valores máximos de redução do título viral de 96,3\% no ensaio 1, $90 \%$ no ensaio 2 e $90 \%$ no ensaio 3. Os efeitos mais expressivos ocorreram nas etapas de adsorção e penetração viral. Os resultados deste trabalho sugerem a importância da quercetina para a medicina veterinária.
\end{abstract}

Palavras-chave: cão, parvovírus, quercetina, antiviral

\begin{abstract}
The in vitro effect of the flavonoid quercetin against canine parvovirus was evaluated. The antiviral activity of quercetin was evaluated by determining the virucidal activity (assay 1), determining the activity on the cell (assay 2) and using the time of addition assay to test the inhibition of the viral replication cycle (assay 3). Quercetin showed a significant antiviral activity, with maximum viral titer reduction of $96.3 \%$ in assay 1 , 90\% in assay 2 and $90 \%$ in assay 3. The most expressive effects occurred in the stages of viral adsorption and penetration. The results show the importance of quercetin for veterinary medicine.
\end{abstract}

Keywords: dog, parvovirus, quercetin, antiviral

\section{INTRODUÇÃO}

O parvovírus canino - canine parvovirus $(\mathrm{CPV})$

- foi primeiramente identificado em 1978 nos Estados Unidos (Appel et al., 1979) e denominado CPV 2. No Brasil, há relatos de infecções causadas pelo parvovírus canino desde 1980 (Hagiwara et al., 1980). O CPV é um vírus não envelopado, fita simples de DNA e possui simetria icosaédrica. Geralmente, a replicação do parvovírus é restrita ao núcleo e dependente das funções celulares. A DNA polimerase, responsável pela síntese da fita complementar desse vírus, é uma polimerase celular expressa em células de mamíferos somente durante a fase S do ciclo celular (Berns, 1990). Desse modo, os parvovírus normalmente desenvolvem tropismo por tecidos altamente ativos mitoticamente, tais como epitélio intestinal, medula óssea e tecidos linfoides (Url e Schmidt, 2005).

O CPV é responsável pela doença viral de maior incidência de enterite hemorrágica em cães (Carmichael e Binn, 1981). A disseminação do CPV ocorre pela via fecal-oral a partir de cães infectados para cães susceptíveis e alcança altos títulos nas fezes dos animais infectados (Pollock, 1982; Carmichael, 1994; Decaro et al., 2005). No intervalo de três a sete dias após a infecção, os cães infectados desenvolvem gastroenterite aguda, caracterizada por perda de apetite, vômitos, febre, diarreia hemorrágica e leucopenia (Decaro et al., 2007a).

Em cães jovens, a maior parte da proteção contra o CPV corresponde à imunização passiva

Recebido em 14 de agosto de 2011 
natural. Após o declínio do título desses anticorpos, os cães se tornam altamente susceptíveis à infecção. A prevenção para a parvovirose canina ocorre mediante vacinação das cadelas prenhes e dos filhotes após seis semanas de idade. As terapias existentes servem apenas para suporte do animal e consistem principalmente na administração de fluidos e eletrólitos e antibioticoterapia para controle de infecções bacterianas secundárias (Martin et al., 2002). Além da ausência de terapêutica eficiente contra o CPV, a vacinação também pode apresentar falhas. Decaro et al. (2007b) relataram o aparecimento de sinais clínicos relacionados com a parvovirose em animais recém-vacinados. De acordo com estes autores, isto pode ser devido à reversão da virulência dos vírus vivos modificados contidos em algumas vacinas.

A quercetina é um dos flavonoides encontrados em maior abundância na natureza (Harborne e Williams, 2000). Além de propriedades antioxidantes, a quercetina também possui atividade antiviral relacionada à capacidade desse composto de se ligar a glicoproteínas do envelope ou ao capsídeo viral, inviabilizando a ligação e a penetração do vírus na célula. A ação da quercetina pode resultar também na redução da replicação ao interferir na síntese do DNA viral (Formica e Regelson, 1995).

A pesquisa de fármacos eficazes e seguros contra esse vírus visa atender à demanda crescente na clínica veterinária pelo sucesso terapêutico no combate à parvovirose. $\mathrm{O}$ objetivo deste trabalho consistiu na avaliação in vitro da atividade antiviral do flavonoide quercetina contra o CPV.

\section{MATERIAL E MÉTODOS}

Para a realização dos ensaios in vitro, foram utilizadas células de linhagem de rins de felino (CRFK). As células foram mantidas em meio essencial mínimo (MEM) (SIGMA-ALDRICH) contendo penicilina, $1,6 \mathrm{mg} / \mathrm{L}$ (CULTILAB), estreptomicina, $\quad 0,4 \mathrm{mg} / \mathrm{L} \quad$ (CULTILAB), suplementadas com soro fetal bovino $10 \%$ (CULTILAB). Foi utilizada uma cepa vacinal de parvovírus canino Cornell-780916-80/ATCC obtida do Laboratório Hertape Ltda. A quercetina [3,3', 4',5,6-Pentahydroxyflavone] (quercetin dihydrate), adquirida da empresa SIGMA-ALDRICH, foi preparada a uma concentração estoque de $10 \mathrm{mg} / \mathrm{mL}$ e armazenada a $-20^{\circ} \mathrm{C}$.

Os vírus foram inoculados em monocamadas semiconfluentes de células CRFK, e após a observação do efeito citopático (ECP), as células foram congeladas e descongeladas duas vezes e centrifugadas a $500 \mathrm{~g}$ por 10 minutos. $\mathrm{O}$ sobrenadante foi coletado e aliquotado (estoque). Esse procedimento foi realizado até que se alcançasse o título viral desejado. Os estoques virais foram titulados pelo método de TCID $_{50}$, como descrito por Reed e Muench (1938).

Monocamadas das células CRFK com tapetes celulares semiconfluentes em microplacas de 96 poços foram tratadas com concentrações de quercetina que variaram de 1 a $90 \mu \mathrm{g} / \mathrm{mL}$ e incubadas em estufa a $37^{\circ} \mathrm{C}$ e atmosfera de $5 \%$ de $\mathrm{CO}_{2}$. As microplacas foram monitoradas sob microscopia óptica, diariamente, durante quatro dias. A citotoxicidade foi determinada pelos efeitos na morfologia e viabilidade celular (perda da monocamada, granulação e vacuolização no citoplasma) em relação ao aspecto das células não tratadas (controle). A citotoxicidade também foi determinada pelo método colorimétrico baseado na redução do 3-[4,5-dimetiltiazol-2-il]2,-difeniltetrazolium brometo (MTT) (SIGMAALDRICH) por enzimas mitocondriais (Mosmann, 1983). No quarto dia após incubação com a quercetina, às células lavadas com tampão fosfato (PBS), $\mathrm{pH} 7,2$, por duas vezes, foi adicionado o MTT, $0,5 \mathrm{mg} / \mathrm{mL}$. As células foram incubadas por quatro horas em estufa a $37^{\circ} \mathrm{C}$ e atmosfera de $5 \%$ de $\mathrm{CO}_{2}$. Posteriormente, o sal formado foi solubilizado pela adição de isopropanol (SIGMA-ALDRICH)-HCl 0,04 N. A densidade óptica $\left(\mathrm{OD}_{550}\right)$ foi determinada por espectrofotometria. A porcentagem de células tratadas viáveis foi calculada em relação ao controle não tratado ( $\%$ de células $=\mathrm{OD}_{\exp } /$ $\mathrm{OD}_{\text {célula controle } \mathrm{X}} 100$ ). Foi determinada a $\mathrm{CT}_{50}$, que é a concentração necessária para reduzir a densidade óptica em 50\%. Com base neste experimento, foi determinada a concentração máxima não tóxica (CMNT) para as células. Para cada concentração de cada composto e para o controle, seis poços foram avaliados, e os resultados foram apresentados como a média desses valores.

Para avaliação do efeito virucida (ensaio 1), os vírus foram incubados com a quercetina em 
concentração que não excedeu a máxima não tóxica. Nos tempos zero, 15, 30, 45 e 60 minutos após incubação, uma alíquota dessa suspensão foi titulada. A atividade antiviral foi determinada pela redução no título viral em relação ao controle e visualizada pela redução do ECP nas células infectadas (Gravina et al., 2010). Como controle de vírus, utilizou-se uma alíquota do CPV submetido aos tempos de incubação, titulados a cada passo, e como controle da substância, incubou-se a quercetina na concentração final utilizada. Foi considerada inibição significativa aquela superior a $1 \log$ (90\% de inibição).

No ensaio 2, avaliou-se a determinação da atividade antiviral em células pré-incubadas com o composto. Desta forma, a infectividade viral foi avaliada segundo prováveis modificações celulares promovidas pela quercetina que possam resultar em resistência celular ao vírus. Para isso, monocamadas das células semiconfluentes em microplacas de 96 poços foram incubadas por $1 \mathrm{~h}$ com a quercetina em diferentes concentrações, inferiores à concentração máxima não tóxica. Após o tempo de incubação, as células foram lavadas por duas vezes com PBS e os vírus foram inoculados. A atividade antiviral foi avaliada pela redução no ECP dos vírus inoculados em monocamadas celulares tratadas em relação aos vírus inoculados em monocamadas celulares não tratadas (controle). Foi considerada inibição significativa aquela superior a $1 \log$.

No ensaio 3, foi investigada a ação inibitória do composto durante o ciclo replicativo viral, segundo método modificado de Serkedjieva e Ivancheva (1999). O efeito antiviral da quercetina foi avaliado mediante a adição dessa substância em diferentes tempos relativos à infecção viral. Monocamadas semiconfluentes de células foram incubadas com MEM ou MEM contendo a quercetina por $1 \mathrm{~h}(-1 \mathrm{~h}$ : prétratamento das células), lavadas duas vezes com PBS e posteriormente inoculadas com diluições do vírus $\left(10-10^{7} \quad\right.$ TCID $\left._{50} / \mathrm{mL}\right)$. Durante a adsorção por $1 \mathrm{~h} \mathrm{a} 4^{\circ} \mathrm{C}$, temperatura que previne a internalização viral, outras placas com células semiconfluentes foram infectadas com diluições do vírus $\left(10-10^{7} \mathrm{TCID}_{50} / \mathrm{mL}\right)$ e tratadas com o composto ( 0 h: efeito na adsorção). Outra fração de células infectadas com CPV $\left(10-10^{7}\right.$ TCID $\left._{50} / \mathrm{mL}\right)$ não tratadas foi incubada a $37^{\circ} \mathrm{C}$ com MEM contendo o composto por $1 \mathrm{~h}$ (1 h: efeito na penetração). Duas horas após a infecção viral, uma outra parcela de células infectadas com CPV (10-10 TCID $\left._{50} / \mathrm{mL}\right)$ foi tratada com o composto diluído em MEM (2h: efeito após a infecção viral). A atividade antiviral de todas as fases foi avaliada após 72 horas de incubação a $37^{\circ} \mathrm{C}$ e $5 \%$ de $\mathrm{CO}_{2}$, pela determinação do título viral, calculado pelo método de Reed e Muench (1938). Foi considerada inibição significativa aquela superior a $1 \log$ (90\% de inibição).

\section{RESULTADOS E DISCUSSÃO}

A CMNT da quercetina foi determinada pela associação da observação microscópica da morfologia celular, com a mensuração da viabilidade dessas mesmas células determinada pelo ensaio de MTT. Com esse objetivo, a quercetina foi incubada em monocamadas semiconfluentes de CRFK e a observação das alterações celulares foi feita por um período de quatro dias por microscopia óptica. Após quatro dias de incubação, a viabilidade celular também foi avaliada pelo método colorimétrico baseado na redução do sal de tetrazolium (MTT) pelas células viáveis. Com isso, foi possível determinar a concentração máxima de trabalho de $5 \mu \mathrm{g} / \mathrm{mL}$. Acima dessa concentração, foi observada vacuolização do citoplasma, morte e desprendimento do tapete celular.

O teste de citotoxicidade para as substâncias com potencial antiviral na pesquisa in vitro é importante para discriminar o efeito citotóxico do efeito antiviral (Schnitzler et al., 2008). Esse teste também é importante para verificar a toxicidade de novos compostos nos estágios iniciais de desenvolvimento de fármacos (Putnam et al., 2002), pois o equilíbrio entre os efeitos farmacológicos e toxicológicos de um composto é um requisito essencial para sua aplicabilidade como futuro agente terapêutico (Melo et al., 2002).

Os resultados da atividade antiviral foram expressos através da identificação do ECP e redução do título viral. No ensaio de determinação da atividade virucida (ensaio 1), observou-se que o título viral sofreu variação a partir do tempo $0 \mathrm{~h}$, com redução máxima de $96,3 \%$ do título (Fig. 1). A concentração de quercetina incubada com o vírus foi de $3 \mu \mathrm{g} / \mathrm{mL}$. 


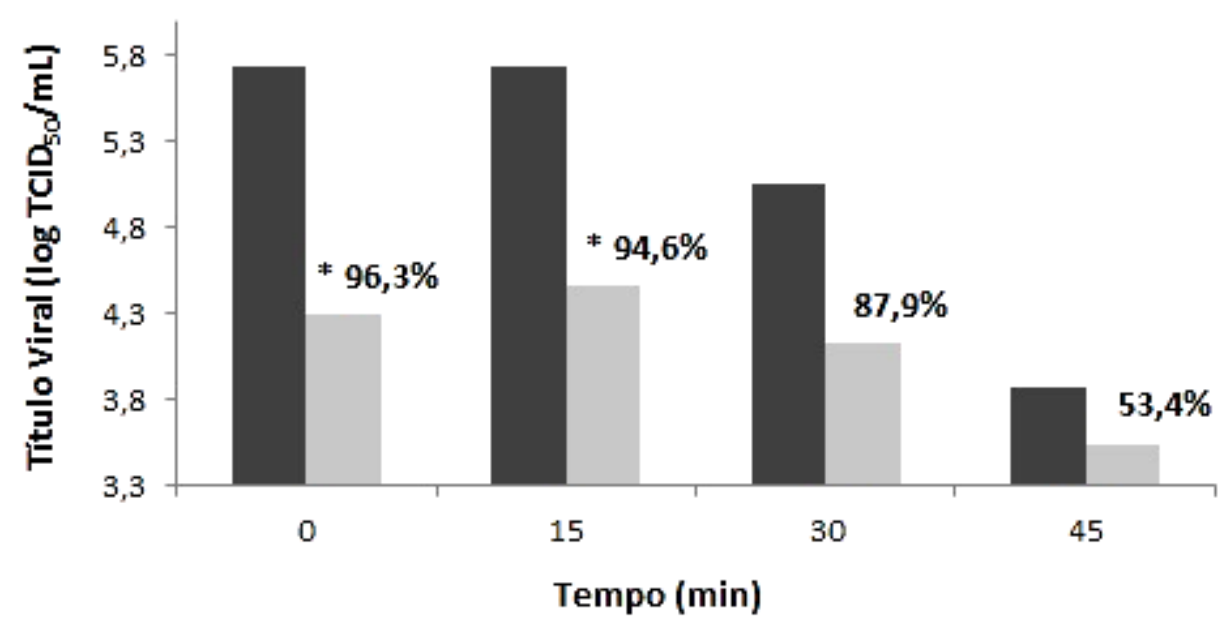

Controle $\quad 3 \mu \mathrm{g} / \mathrm{mL}$ Quercetina

Figura 1. Atividade virucida da quercetina $(3 \mu \mathrm{g} / \mathrm{mL})$ sobre o parvovírus canino avaliada em diferentes tempos $(0,15,30$ e 45 minutos $)$ - ensaio 1 . Valores correspondentes à porcentagem de redução do título viral em relação ao controle. * Inibição significativa ( $\geq 1 \log , 90 \%)$.

No ensaio de determinação de atividade sobre as células (ensaio 2), as concentrações utilizadas foram de $0,5 \mu \mathrm{g} / \mathrm{mL}, 1 \mu \mathrm{g} / \mathrm{mL}$ e $1,5 \mu \mathrm{g} / \mathrm{mL}$. Observou-se redução do título viral significativa e dose-dependente (Fig. 2). Houve redução máxima de $90 \%$ do título viral para a concentração de $1,5 \mu \mathrm{g} / \mathrm{mL}$ de quercetina.

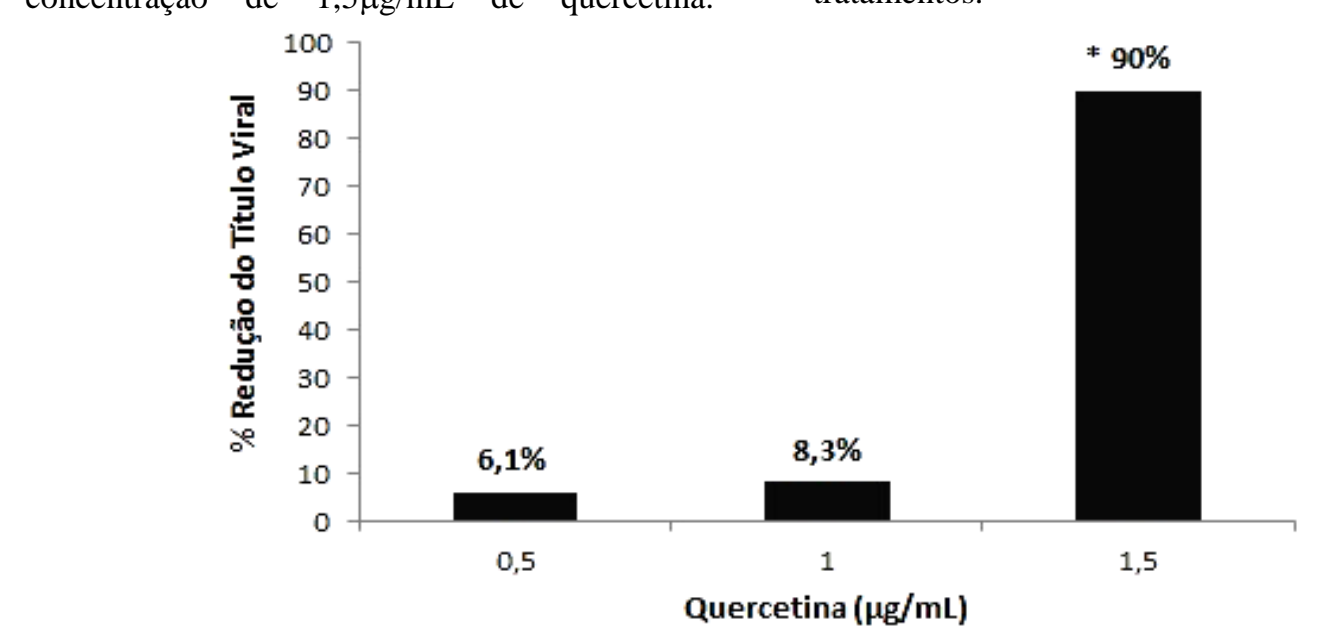

Possivelmente, a quercetina se liga a receptores celulares ou a outras estruturas moleculares, causando, assim, modificações celulares duradouras, de forma a diminuir a infectividade por resistência celular ao vírus, mesmo após a retirada das diluições dos tratamentos.

Figura 2. Efeito da adição da quercetina $(0,5,1$ e $1,5 \mu \mathrm{g} / \mathrm{mL})$ sobre células CRFK antes da inoculação pelo parvovírus canino - ensaio 2. Valores correspondentes à porcentagem de redução do título viral em relação ao controle. * Inibição significativa ( $\geq 1 \log , 90 \%)$.

A atividade antiviral da quercetina pode estar relacionada a mecanismos de entrada do vírus na célula. A desestabilização das partículas virais pela quercetina pode, de certa forma, dar-se sobre os receptores virais, impedindo a ligação do vírus à célula-alvo. 
Para melhor avaliar a interferência da quercetina nos mecanismos replicativos do $\mathrm{CPV}$, foi realizado o terceiro ensaio. Neste ensaio, a quercetina foi incubada em uma concentração de $2,0 \mu \mathrm{g} / \mathrm{mL}$ a cada passo da infecção viral, ou seja, antes da inoculação $(-1 \mathrm{~h})$, no momento da adsorção $(0 \mathrm{~h})$, no momento da penetração $(1 \mathrm{~h})$, e após a entrada do vírus $(2 \mathrm{~h})$. O teste evidenciou redução máxima de $90 \%$ do título viral na etapa de penetração $(1 \mathrm{~h})$, no entanto as porcentagens de redução foram também expressivas para as etapas de adsorção $(0 \mathrm{~h})$ e pós-infecção (2 h), embora não significativas, considerando-se o critério mínimo de redução de 90\% do título viral (Fig. 3). Estes resultados indicam que, além de possuir atividade virucida, a quercetina pode, respectivamente, interferir na ligação do vírus ao seu receptor celular e no processo de internalização nas células. Por meio da inibição do processo de penetração viral nas células, a atividade antiviral demonstrada pela quercetina permite a redução do número de novas células infectadas, o controle da propagação viral e a formação de novas progênies.

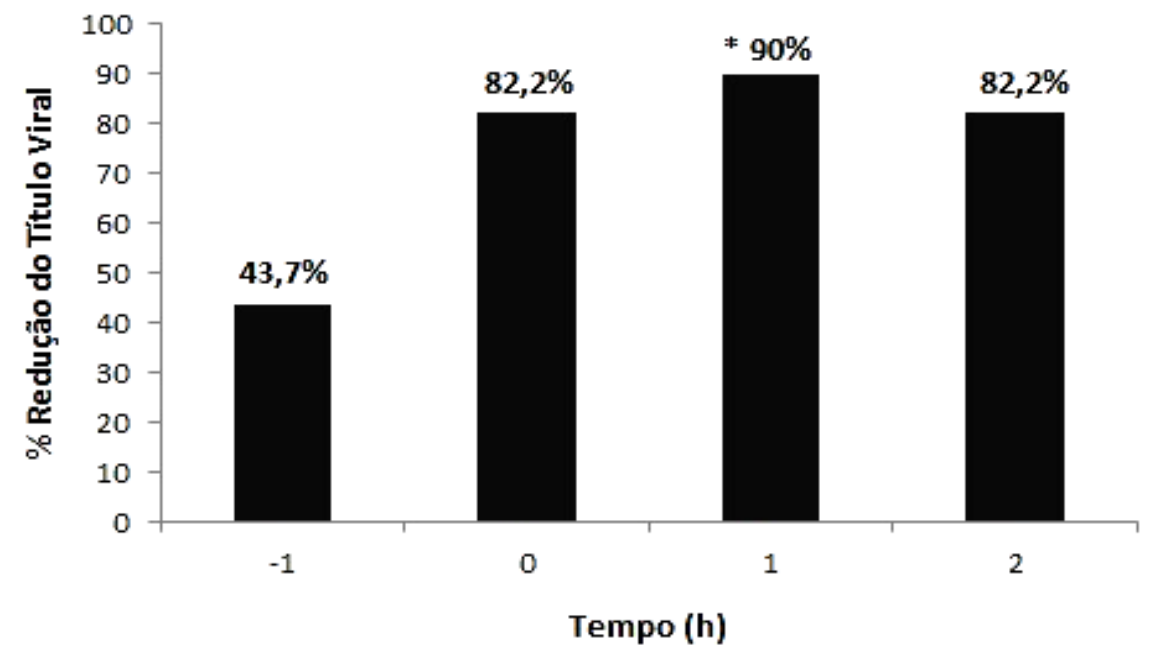

Figura 3. Efeitos inibitórios da adição de quercetina sobre diferentes etapas do ciclo replicativo do parvovírus canino. A quercetina $(2 \mu \mathrm{g} / \mathrm{mL}$ ) foi adicionada em diferentes tempos: - $1 \mathrm{~h}$ (efeito de prétratamento), $0 \mathrm{~h}$ (efeito na adsorção), $1 \mathrm{~h}$ (efeito na penetração) e $2 \mathrm{~h}$ (efeito pós-infecção). Valores correspondentes à porcentagem de redução do título viral em relação ao controle. * Inibição significativa $(\geq 1 \log , 90 \%)$.

Os ensaios demonstraram o potencial da quercetina sobre a estrutura do CPV. Isso caracteriza a quercetina como possível composto ativo contra o $\mathrm{CPV}$, com efeito antiviral já relatado contra outros vírus, como HHV-1 e HHV-2 (Chiang et al., 2003) e EHV-1 (Gravina et al., 2010).

\section{CONCLUSÕES}

O presente estudo demonstra que o flavonoide quercetina exibiu propriedades antivirais in vitro sobre o parvovírus canino. A atividade virucida da quercetina e seu efeito inibitório em etapas iniciais da replicação do parvovírus canino podem estar relacionados à inativação direta do vírus por meio da ligação desse composto a estruturas virais essenciais para a infecção. A quercetina também interferiu na infectividade viral ao induzir as células a um estado de menor susceptibilidade ao vírus. Estes resultados sugerem o uso potencial desse flavonoide como candidato a agente terapêutico no controle da parvovirose canina.

\section{AGRADECIMENTOS}

Os autores agradecem à FAPEMIG (Fundação de Amparo à Pesquisa do Estado de Minas Gerais) e ao CNPq (Conselho Nacional de Desenvolvimento Científico e Tecnológico) pelo apoio financeiro a este trabalho. 


\section{REFERÊNCIAS}

APPEL, M.J.G.; SCOTT, W.F.; CARMICHAEL, L.E. Isolation and immunization studie of canine parvo-like virus from dogs with haemorrhagic enteritis. Vet. Rec., v.105, p.156-159, 1979.

BERNS, K.I. Parvovirus Replication. Microbiol. Rev., v.54, p.316-329, 1990.

CARMICHAEL, L.E. Canine parvovirus type-2. An evolving pathogen of dogs. Ann. Vet. Med., v.135, p.459-464, 1994.

CARMICHAEL, L.E.; BINN, L.N. New enteric virus in the dog. Adv. Vet. Sci. Comp. Med., v.25, p.1-27, 1981.

CHIANG, L.C.; CHIANG, W.; LIU, M.C. et al. In vitro antiviral activities of Caesalpinia pulcherrima and its related flavonoids. $J$. Antimicrob. Chemother., v.52, p.194-198, 2003.

DECARO, N.; DESARIO, C.; ELIA, G. et al. Occurrence of severe gastroenteritis in pups after canine parvovirus vaccine administration: A clinical and laboratory diagnostic dilemma. Vaccine, v.25, p.1161-1166, 2007b.

DECARO, N.; ELIA, G.; MARTELLA, V. et al. A real-time PCR assay for rapid detection and quantification of canine parvovirus type 2 DNA in the feces of dogs. Vet. Microbiol., v.105, p.1928, 2005.

DECARO, N.; MARTELLA, V.; ELIA, G. et al. Tissue distribution of the antigenic variants of canine parvovirus type 2 in dogs. Vet. Microbiol., v.121, p.39-44, 2007a.

FORMICA, J.V.; REGELSON, W. Review of biology of quercetin and related bioflavanoids. Food Chem. Toxicol., v.33, p.1061-1080, 1995.

GRAVINA, H.D; TAFURI, N.F.; SILVA JÚNIOR, A. et al. In vitro assessment of the antiviral potential of transcinnamic acid, quercetina and morin against equid herpesvirus 1. Res. Vet. Sci., v.91, p.158-162, 2010 .

HAGIWARA, M.K.; JULY, J.R.; BACARO, M.R. et al. Enterite hemorrágica em case associada à infecção por um parvovírus. Arq. Inst. Biol., v.47, p.47-49, 1980.
HARBORNE, J.B.; WILLIAMS, C.A. Advances in flavonoid research. Phytochem., v.55, p.481504, 2000.

MARTIN, V.; NAJBAR, W.; GUEGUEN, S. et al. Treatment of canine parvoviral enteritis with interferon-omega in a placebo-controlled challenge trial. Vet. Microbiol., v.89, p.115-127, 2002.

MELO, P.S.; MARIA, S.S.; VIDAL, B.C. et al. Violacein cytotoxicity and induction of apoptosis in V79 cells. In vitro Cell. Dev. - An., v.36, p.639-543, 2002.

MOSMANN, T. Rapid Colorimetric assay for cellular growth and survival: application to proliferation and citotoxicity assays. J. Immunol. Methods, v.65, p.55-63, 1983.

POLLOCK, R.V. Experimental canine parvovirus infection in dogs. Cornell Vet., v.72, p.103-119, 1982.

PUTNAM, K.P.; BOMBICK, D.W.; DOOLITTLE, D.J. Evaluation of eight in vitro assays for assessing the cytotoxicity of cigarette smoke condensate. Toxicol. In Vitro, v.16, p.599-607, 2002.

REED, J.H.; MUENCH, H. A simple method for estimating fifty percent endpoints. Am. J. Hyg., v.27, p.493-496, 1938.

SERKEDJIEVA, J.; IVANCHEVA, S. Antiherpes virus of extracts from the medicinal plant Geranium sanguineum L. J. Ethnopharmacol., v.64, p.59-68, 1999.

SCHNITZLER, P.; NOLKEMPER, S.; STINTZING, F.C. et al. Comparative in vitro study on the antiherpetic effect of phytochemically characterized aqueous and ethanolic extracts of Salvia officinalis grown at two different locations. Phytomedicine, v.15, p.62-70, 2008.

URL, A.; SCHIMIDT, P. Do canine parvoviruses affect canine neurons? An immunohistochemical study. Res. Vet. Sci., v.79, p.57-99, 2005. 